\title{
Salivary Biomarkers for Detection of Oral Squamous Cell Carcinoma: Current State and Recent Advances
}

\author{
Maha Yakob • Laurel Fuentes • Marilene B. Wang • \\ Elliot Abemayor • David T.W. Wong
}

Published online: 21 March 2014

(C) Springer International Publishing AG 2014

\begin{abstract}
Oral squamous cell carcinoma (OSCC) is the most common malignant neoplasm of the oral cavity. Detection of OSCC is currently based on a thorough clinical oral examination combined with a biopsy for histological analysis. Most cases of OSCC are not detected until the cancer has developed into advanced stages; thus, a reliable early-stage diagnostic marker is needed. This literature review presents an overview of the status of current advances in salivary diagnostics for OSCC. Though many protein and mRNA salivary biomarkers have been identified that can detect OSCC with high sensitivity and specificity, the most discernable findings occur with the use of multiple markers. Studies that incorporate proteomic, transcriptomic, and potentially additional "omics", including methylomics, need to be initiated to bring technology to clinical applications and allow the best use of saliva in diagnosing OSCC.
\end{abstract}

\footnotetext{
M. Yakob $\cdot$ L. Fuentes $\cdot$ D. T. Wong $(\bowtie)$

Center for Oral/Head \& Neck Oncology Research, School of Dentistry, University of California, Los Angeles, 73-017 CHS, 10833 Le Conte Avenue, Los Angeles, CA 90095, USA

e-mail: dtww@ucla.edu

M. Yakob

e-mail: myakob@ucla.edu

L. Fuentes

e-mail: 1fuentes@dentistry.ucla.edu

M. B. Wang • E. Abemayor

Department of Head and Neck Surgery, David Geffen School of Medicine at University of California Los Angeles, Los Angeles, CA, USA

M. B. Wang

e-mail: mbwang@ucla.edu

E. Abemayor

e-mail: abemayor@ucla.edu
}

Keywords Salivary diagnostics $\cdot$ Salivary biomarker $\cdot$ Oral fluid diagnostics · Oral squamous cell carcinoma · Oral cancer . Salivaomics $\cdot$ Transcriptomics · Proteomics $\cdot$ Microbiomics · Methylomics $\cdot$ Metabolomics $\cdot$ Exosomes

\section{Introduction}

Oral cancers account for $2-4 \%$ of all cancer cases worldwide, with approximately 40,000 new cases and 8,000 deaths in the US in 2013 [1-5]. Oral squamous cell carcinomas (OSCCs) represent the most frequent of all oral neoplasms, and more than $90 \%$ of all oral neoplasms are estimated to be OSCC [6, 7]. The 5-year survival rate of oral cancer is $60-80 \%$ when detected during its early stages $[1,7]$.

OSCC is acquired from a combination of environmental risk factors and genetic predispositions. In combination with an individual's genetics, exposure to tobacco, alcohol, and radiation, among other carcinogens, has the ability to mutate oncogenes that are in charge of cell survival and proliferation [8-10]. Clinically defined lesions of the oral mucosa have a higher oncogenic risk than normal oral mucosa. Lesions termed leukoplakia, erythroplakia, and leukoerythroplakia are potentially malignant lesions of the aerodigestive tract [11]. These lesions are defined as dysplasia of variable grades when verified with cellular atypia but without invasion. However, the values that predict cancer occurrence are a matter of debate because OSCC can arise where any epithelial dysplasia is detected [12].

Surgery and radiotherapy are currently the primary treatments. Surgical therapy has significant effects on swallowing, speech, and physical appearance, greatly affecting the patient's quality of life. Patients who have undergone treatment for OSCC are followed up regularly to detect recurrence. Recurrence occurs in 15-33\% of patients [13, 14], with local recurrence being more common; thus, an improved diagnostic 
tool to predict which patients are most at risk for OSCC recurrence is needed $[13,15]$

Detection of OSCC is currently based on a thorough clinical oral examination combined with a biopsy for a histological examination if an abnormal area is detected. The location from which the biopsy sample is taken is crucial for histopathological verification of the oral cancer. However, selecting the right location is difficult because of the nonuniform appearance of cancerous and precancerous lesions.

DNA mutations have also been observed in epithelial cells with no evidence of histopathological changes, showing that the current tools for detecting altered epithelial cells, such as a clinical examination and histopathology, are not enough for predicting areas at high risk of developing oral cancer [16-18].

Early detection and diagnosis lead to a greater survival rate and play a significant role in successful clinical treatment. Most OSCC cases are detected when the cancer has developed into the advanced stages. Some lesions are difficult to detect in a general examination if located in hard-to-find regions. Delayed detection may account for the high morbidity rate of OSCC [7, 19, 20]. OSCC is particularly hard to diagnose early because the early stages may be painless and a burning sensation may not develop until the neoplasm has advanced [2]. This literature review presents an overview of the advances and most recently published papers on salivary diagnostics for OSCC.

\section{Saliva Composition and Method of Collection}

Whole saliva (WS) is a mixture of fluids produced and secreted by major and minor salivary glands in the mouth and throat. WS contains proteins, microorganisms, cellular debris, gingival crevicular fluid, and serum components [21]. The paired major glands include the parotid, submandibular, and sublingual glands and account for the majority of saliva volume [22]. However, the minor glands, which produce less than $10 \%$ of the total saliva volume, comprise most of the mucosal protective component of saliva. The mucosal salivary glands are responsible for making mucins, a class of salivary glycoproteins that layer and lubricate dental surfaces to protect the mucosa from mechanical wear, and they have antiviral, antifungal, and antibacterial implications [23]. The main component of saliva is water $(99.5 \%)$, with proteins $(0.3 \%)$ and inorganic species $(0.2 \%)$ making up a small portion of WS. Salivary analysis is inherently challenging because not only are the potential biomarkers available in small amounts, but the concentrations of different markers vary from milligrams to picograms per milliliter [21, 24].

Saliva collection is non-invasive, simple, and rapid. Saliva can be collected in two ways: "unstimulated" or "stimulated". Unstimulated WS is collected by draining or drool, spitting, suction, or swab. Stimulated saliva is collected by providing the patients with a stimulant agent, such as citric acid, paraffin, or a gum base. With stimulated collection, saliva is obtained primarily from the parotid gland, whereas unstimulated (resting) saliva is produced primarily by the submandibular gland, with minor contributions from the parotid and sublingual glands $[25,26]$. In addition, stimulation of saliva production decreases the concentration of small molecules, such as myoglobin, changing the total composition of the analyzed saliva in favor of larger molecules [27]. Thus, unstimulated saliva is more favorable for biomarker discovery and has been used in most diagnostic studies [28].

\section{Translational Applications of Salivary Diagnostics}

Saliva is a multi-constituent oral fluid capable of mirroring both oral and systemic health conditions. Salivary analysis has been shown to be a useful diagnostic tool for other distant malignancies, including breast cancer [29], lung cancer [30-32], Sjögren syndrome [33], and pancreatic cancer [34, 35].

Saliva contains biomarkers, which can be used as indicators of disease. According to the National Institutes of Health $(\mathrm{NIH})$, a biomarker is a characteristic that is objectively measured and evaluated as an indicator of a normal biological process, pathogenic process, or pharmaceutical response to therapeutic intervention. A biomarker must be verified and validated before it can be used in a clinical assay and have any impact or application in health risk assessment [36, 37].

In biomarker research, the sensitivity and specificity of a marker must be determined in each study. Sensitivity is the true-positive rate, which is described by the percentage of the total number of people with the disease that test positive. Specificity is the true-negative rate, which measures the proportion of individuals that test negative for the disease that actually do not have the disease. The area under the receiver operating characteristics curve (AUC) is also an important measurement when reporting biomarker performance. The AUC for a biomarker diagnostic test can range from $50 \%$, which correlates to having no better insight than chance alone, to $100 \%$, which denotes a perfect diagnostic test $[38,39]$.

\section{Current State of Oral Squamous Cell Carcinoma-specific Salivary Biomarkers}

Given that saliva is in direct contact with the oral mucosa and cancerous lesions, the screening and detection of early OSCC lesions using saliva has promise. Salivary diagnostics may avoid many unnecessary biopsies, as well as hospital and outpatient clinical visits. Existing therapy for OSCC patients is based on traditional stage-predicting guides (mostly the TNM [tumor, node, metastasis] criteria) and histological grading [40-43]. An important advancement in salivary 
diagnostics is the development of omics-based biomarkers. The term salivaomics was coined to reflect the rapid development of translational and clinical tools based on salivary biomarkers [44•].

\section{Proteomics}

Recent developments in proteomic technologies, such as mass spectrometry, liquid chromatography, and protein/peptide labeling technologies, allow the detection of low abundance molecules in the saliva proteome $[45,46]$. Numerous studies have reported that the proteomic profile of saliva from OSCC patients differs from the profile for OSCC-free controls (Table 1).

In 2008, 1,166 salivary proteins were initially identified in a National Institute of Dental and Craniofacial Researchfunded project that sought to catalog and annotate the human salivary proteome [47]. This project was an essential first step for saliva to be clinically useful in disease diagnosis and health monitoring. The majority of the proteins are synthesized and subsequently secreted into the oral cavity by the salivary gland acinar cells [48]. This observation suggests that proteomic constituents of saliva are products of the salivary glands, which may be subject to internal and external factors. Consequently, the salivary proteome has been useful for identifying biomarkers for both local and distant diseases [49].
The matrix metalloproteinases (MMPs) may play a key role in cancer development, as they cause degradation of the extracellular matrix and basement membranes. MMPs have been studied as potential cancer biomarkers and been associated with tumor invasion and metastasis [50]. In a recent study, Stott-Miller et al. determined whether salivary concentrations of the most highly differentially expressed MMPs could be used as a diagnostic aid. The concentrations of MMP1 and MMP3 were tested in saliva samples from 100 subjects (60 primary OSCC cases, 15 dysplasia cases, and 25 controls). The protein concentrations were higher in the saliva from OSCC patients compared with the saliva from cancer-free controls [51]. In another study, MMP-9 levels were elevated in 19 tongue cancer patients, as well as the levels of carbonyls, mammary serine protease inhibitor (Maspin), and Cyclin D1 [52]. The tongue is the most common site of OSCC, accounting for almost half of all OSCC cases [42, 53].

Cytokines are intercellular signaling proteins that play a role in normal growth, cellular proliferation, tissue repair, and angiogenesis. Cytokines are also involved in the immune response against infection and inflammation. Rheumatoid arthritis, osteoporosis, diabetes mellitus, and periodontal disease can increase inflammatory protein levels. However, interleukin (IL)-8 levels have been reported to be significantly higher in saliva from OSCC patients compared with patients with severe periodontal disease. Both IL-1 $\beta$ and IL-8 were reported to be significantly higher in OSCC patients compared

Table 1 Recent publications of proteomic biomarkers for oral squamous cell carcinoma (OSCC)

\begin{tabular}{|c|c|c|c|}
\hline Biomarkers & Function & Reference & $\begin{array}{l}\text { Sensitivity }(\%) / \text { specificity } \\
(\%) / \text { AUC }\end{array}$ \\
\hline Interleukin- $1 \alpha$ & Protein & [54] & $\mathrm{NR} / \mathrm{NR} / \mathrm{NR}\left({ }^{*} p<0.0001\right)$ \\
\hline Interleukin-1 $\beta$ & Protein & {$[55,65 \bullet \bullet]$} & $75 / 80 / 0.77$ \\
\hline Interleukin-6 & Protein & {$[54]$} & $\mathrm{NR} / \mathrm{NR} / \mathrm{NR}\left({ }^{*} p<0.0001\right)$ \\
\hline Interleukin-8 & Protein & {$[54,55,65 \bullet \bullet]$} & $75 / 80 / 0.77$ \\
\hline Tumor necrosis factor- $\alpha$ & Protein & {$[54]$} & $\mathrm{NR} / \mathrm{NR} / \mathrm{NR}\left({ }^{*} p<0.0001\right)$ \\
\hline Vascular endothelial growth factor-A & Protein & {$[54]$} & $\mathrm{NR} / \mathrm{NR} / \mathrm{NR}\left({ }^{*} p<0.0001\right)$ \\
\hline Matrix metalloproteinase-1 & Protein & {$[51]$} & $\mathrm{NR} / \mathrm{NR} / \mathrm{NR} / 0.845$ \\
\hline Matrix metalloproteinase-3 & Protein & {$[51]$} & $\mathrm{NR} / \mathrm{NR} / \mathrm{NR} / 0.8766$ \\
\hline Carbonyls & Products of protein oxidation & {$[52]$} & $90 / 80 / \mathrm{NR}$ \\
\hline Mammary serine protease inhibitor (Maspin) & Protein & {$[52]$} & $100 / 100 / \mathrm{NR}$ \\
\hline Cyclin D1 & Protein & {$[52]$} & $100 / 100 / \mathrm{NR}$ \\
\hline Transferrin & Protein & {$[45,57]$} & NR, $100 / 95 / 0.91-0.95^{* *}$ \\
\hline Total sialic acid & Protein & {$[62]$} & $61 / 44 / 0.653$ \\
\hline$\alpha$-L-fucosidase & Protein & {$[62]$} & $69 / 48 / 0.696$ \\
\hline Actin & Protein & {$[56]$} & $100 / 75 / \mathrm{NR}$ \\
\hline Basic fibroblast growth factor & Protein & {$[61]$} & $67 / 83 / \mathrm{NR}$ \\
\hline \multicolumn{4}{|l|}{ Combination: } \\
\hline $\begin{array}{l}\text { Myeloid-related protein } 14+\text { profilin }+ \text { CD59 }+ \text { catalase }+ \\
\text { Mac-2-binding protein }\end{array}$ & Protein combination & {$[55]$} & $90 / 83 / 0.93$ \\
\hline
\end{tabular}


with matched healthy control subjects. The research group used Luminex xMAP, which was shown to be as effective as enzyme-linked immunosorbent assay (ELISA) for the quantification of saliva proteins. Luminex XMAP technology has the advantage of high sensitivity, throughput, and efficiency, and is less time consuming than ELISA [46]. In a study focusing on tongue squamous cell carcinoma (TSCC) and salivary biomarkers, five cytokines (IL-1 $\alpha$, IL-6, IL-8, vascular endothelial growth factor-A, and tumor necrosis factor- $\alpha$ ) were elevated in patients with TSCC compared with controls [54].

In 2008, a panel of candidate protein biomarkers for the detection of OSCC was identified by immunoassay validation. The combination of five candidate protein markers, myeloidrelated protein 14 (MRP14), profiling, CD59, catalase, and Mac-2-binding protein (M2BP), had a sensitivity of $90 \%$ and specificity of $83 \%$ for OSCC detection, showing that the proteomic profile of saliva from OSCC patients differs from that of OSCC-free controls [55]. Mass spectrometry-based proteomics was used to discover differences in salivary protein abundance between subjects with pre-malignant and malignant oral lesions. Biochemical validation showed that myosin and actin are promising salivary biomarkers capable of discriminating malignant oral lesions. Actin and myosin are key cytoskeletal proteins that facilitate cell motility and invasion, behavior central to epithelial tumorigenesis [56].

In another study, salivary biomarkers for early-stage OSCC were identified by two-dimensional gel electrophoresis and mass spectrometry, and then validated by Western blot analysis and ELISA. Transferrin levels were elevated in the saliva from a mostly male sample of 41 OSCC patients compared with 30 OSCC-free controls. The increase in salivary transferrin correlated with increasing tumor size. Transferrin is needed for the growth of rapidly growing cells and is involved in DNA synthesis, electron transport, mitogenic signaling pathways, proliferation, and cell survival [57].

Fibroblast growth factors (FGFs) are heparin-binding proteins involved in angiogenesis, wound healing, embryonic development, and various endocrine signaling pathways. FGFs are key players in the proliferation and differentiation of a wide variety of cells and tissues. Basic FGF (bFGF) is a solid mitogen that stimulates the proliferation of cells of mesodermal and neuroectodermal origin and is reported to be involved in wound healing, hematopoiesis, angiogenesis, and tumor progression [58-60]. Salivary bFGF levels were found to be significantly elevated in patients newly diagnosed with OSCC compared with healthy controls. The findings suggest that bFGF could be a potential biomarker for the detection of OSCC in patients with no oral mucosal disease, such as oral lichen planus, geographic tongue, aphthous ulcer, or candidiasis. Salivary bFGF could also be used to detect recurrence, as the levels have been reported to be higher in patients with newly diagnosed OSCC than in those who had completed treatment and not exhibited any recurrence for at least 2 years [61].
Another recent study compared the ratio of total sialic acid to total protein (TSA/TP) and alpha-L-fucosidase activity in saliva from patients with cancer in the oral cavity, those with oral precancerous conditions, and healthy controls. The salivary TSA/TP and alpha-L-fucosidase activity were significantly increased in patients with precancerous conditions and cancer compared with the controls $(p=0.005$ and $p=0.001$, respectively) [62].

\section{Transriptomics}

Evaluation of the salivary transcriptome and extracellular RNA is an emerging diagnostic technology because of its discriminatory power for disease detection. High-throughput microarray technology has made the investigation of gene expression on a genome-wide level feasible and routine. In 2004 , microarray analysis showed that more than 1,600 genes are significantly differentially expressed in saliva from OSCC patients and controls [63]. This pioneering study provided salivary transcriptome diagnostics with new opportunities for the early diagnosis of oral cancer and other human diseases. That study reported potential salivary RNA biomarkers, and the combinations of these biomarkers yielded a sensitivity of $91 \%$ and a specificity of $91 \%$ for distinguishing OSCC from controls [63]. Recently, these biomarkers were studied again in a Serbian population and five independent cohort populations in Los Angeles [64••, 65••]. The RNA biomarkers included $I L-8, I L-1 \beta$, dual specificity phosphatase 1 (DUSP1), ornithine decarboxylase antizyme 1 (OAZ1), spermidine/spermine N1-acetyltransferase 1 (SAT1), and S100 calcium binding protein $\mathrm{P}(S 100 P)$. The sensitivity and specificity of the combination of biomarkers remained high in both cases, further enforcing the necessity to use multiple different biomarkers for early OSCC detection with salivary biomarkers. Additional studies have reported new transcriptomic biomarkers for OSCC that may increase the feasibility of using saliva for discriminatory OSCC detection in future combination biomarker studies (Table 2).

MMP transcripts have been found to be over-expressed in OSCC patients [66, 67], and $M M P-1$ and $M M P-9$ have been associated with the progression of dysplasia to cancer [68]. $M M P-1$ transcript levels in saliva have been shown to be higher in OSCC patients than controls [51, 69].

Micro-RNAs (miRNAs) are regarded as important regulators of mRNA and protein expression and are predicted to regulate the expression of almost one-third of all human transcripts [70, 71]. miRNAs can function as either tumor suppressors or oncogenes depending on their target transcripts. Numerous studies have described the potential of miRNAs as cancer biomarkers for oral cancer [72, 73]. In a recently published study, approximately 50 miRNAs were detected in saliva using reverse transcriptase-preamplification-quantitative 
Table 2 Recent publications of transcriptomic biomarkers for oral squamous cell carcinoma

\begin{tabular}{|c|c|c|c|}
\hline Biomarker & Function & Reference & Sensitivity (\%)/specificity (\%)/AUC \\
\hline Matrix metalloproteinase-1 & mRNA & {$[51]$} & NR/NR/0.984 \\
\hline Interleukin-8 (IL-8) & mRNA & {$[65 \bullet \bullet]$} & $66 / 80 / 0.77$ \\
\hline S100 calcium binding protein $P$ & mRNA & {$[65 \bullet \bullet]$} & $54 / 88 / 0.71$ \\
\hline Spermidine/spermine N1-acetyltransferase $1(S A T 1)$ & mRNA & {$[65 \bullet \bullet$} & $54 / 82 / 0.70$ \\
\hline Omithine decaboxylase antizyme $1(O A Z 1)$ & mRNA & {$[65 \bullet \bullet]$} & $40 / 92 / 0.60$ \\
\hline Interleukin- $1 \beta(I L-1 \beta)$ & mRNA & {$[65 \bullet \bullet$} & $83 / 76 / 0.83$ \\
\hline Dual specificity phosphatase $1(D U S P 1)$ & mRNA & {$[65 \bullet \bullet$} & $14 / 98 / 0.41$ \\
\hline$m i R-200 a$ & miRNA & {$[74 \bullet \bullet]$} & $\mathrm{NR} / \mathrm{NR} / 0.65$ \\
\hline $\operatorname{miR}-125 a$ & miRNA & {$[74 \bullet \bullet]$} & $\mathrm{NR} / \mathrm{NR} / 0.62$ \\
\hline$m i R-31 i$ & miRNA & {$[72]$} & $80 / 68 / 0.82$ \\
\hline \multicolumn{4}{|l|}{ Combinations: } \\
\hline$I L-1 \beta+S A T 1+D U S P 1$ & mRNA & {$[65 \bullet \bullet$} & $89 / 78 / 0.86$ \\
\hline$I L-8+I L-1 \beta+S A T 1+O A Z 1$ & mRNA & {$[64 \bullet \bullet]$} & $79 / 77 / 0.86$ \\
\hline
\end{tabular}

polymerase chain reaction. In addition, significantly lower levels of $m i R-125 a$ and $m i-R 200 a$ were found in the saliva from 50 OSCC patients compared with 50 healthy control subjects $[74 \bullet \bullet, 75]$. Salivary $m i R-31$ increased significantly in patients with OSCC at all stages, and then decreased after the cancer had been excised. Along with the increased miR-31 in plasma, saliva and blood diagnostics may also lead to powerful OSCC biomarker prediction and disease progression [72].

\section{Microbiomics}

Bacterial infections were previously connected to malignancies because of their ability to promote chronic inflammation $[76,77]$. A recent study compared the microbial species from the tumor and non-tumor tissues of patients with OSCC using denaturing gradient gel electrophoresis, cloning, and sequencing. Peptostreptococcus stomatis, Streptococcus gordonii, and six other named cultivable bacterial species were found to be highly associated with tumor sites, whereas Granulicatella adiacens, a known factor in endocarditis, was prevalent at non-tumor sites. The same microbial diversity was found in the saliva of patients with OSCC. Noting the changes in oral microbiota, species colonization may aid in determining the evolution of pre-cancerous lesions into OSCC malignancies, for use as a diagnostic tool. Further research of the most prevalent species identified in tumor tissues is needed to formulate their role in cancer development [78, 79•].

Human papilloma virus (HPV) is associated with oropharyngeal squamous cell cancers, and $60 \%$ in the US have been shown to be positive for HPV type 16. Current tests for HPV detection by saliva are available using polymerase chain reaction [80]. As early diagnosis is critical for OSCC, further advancements in creating point-of-care technologies for HPVassociated OSCC detection are likely to occur.

\section{Methylomics}

Methylation has been suggested to be an early event in oral carcinogenesis. In OSCC, hypermethylated genes have been associated with alterations in proliferation, DNA repair, apoptosis, cell-cell adhesion, and angiogenesis, suggesting them as potential biomarkers for oral cancer $[81,82 \bullet \bullet$. A genomewide DNA methylation platform was used to uncover differentially methylated genes in saliva from OSCC patients and normal controls. This phase I Biomarker Development Trial identified Homeobox protein Hox-A9 (HOXA9) and nidogen 2 (NID2) as methylated genes in OSCC patients. Thus, promoter methylation of genes in saliva may serve as potential biomarkers for the early detection of OSCC [83].

\section{Metabolomics}

Metabolomics is a measure of all intracellular metabolites and is a potent tool for understanding cellular function [84, 85]. Metabolomics-based technology is emerging for the identification of disease-associated salivary analytes. Sugimoto et al. published a novel study in which they compared the salivary metabolic profiles of patients with oral cancer and healthy controls. Twenty-eight metabolites, including pyrroline, choline, and valine, were found to be discriminatory between subjects with oral cancer and healthy controls [34].

Cancer is often correlated with an altered glucose metabolism. Most cancer cells have a high rate of aerobic glycolysis, also referred to as the Warburg effect, for the generation of 
adenosine triphosphate, resulting in increased lactate production. A research group from the University of Michigan recently performed global metabolic profiling of metabolites in head and neck squamous cell carcinoma subjects. The metabolites associated with malignant transformation of head and neck neoplasia could be related to the Warburg effect [86]. Further investigation into the metabolomics and the biological importance in oral cancer is needed.

\section{Exosomes and Circulating Biomarkers}

Lately, interest in the biology of extracellular vesicles has increased greatly. miRNA is one of the most commonly identified genetic materials in exosomes. Exosomes are regarded as a novel mechanism by which cancer cells and virally infected cells can regulate their micro-environment. Exosomes and microvesicles (MVs) are nanometer-sized membranous vesicles secreted from many cell types into their surrounding extracellular space and body fluids [87]. Exosomes and MVs have also been found in saliva $[88,89]$. Studies have examined the biological activity and molecular functions of MVs in oral cancer progression [28,90], but biofluids have different properties and contain a wide range of exosomes and MVs secreted from various cell types. The cell culture supernatant is an ideal model for exosome purification. However, the viscosity and cellular contamination of WS make it a less than ideal medium for exosome isolation $[28,90]$.

\section{Concluding Remarks and Areas for Further Research}

Saliva has become a more and more attractive tool because of the advances in novel technology and its potential for the surveillance of general health and disease. Sensitive technology is needed to detect biomarkers in low quantities for saliva to be an effective diagnostic medium [91]. Engineers are now pioneering and advancing the development of an electrochemical biosensor capable of identifying salivary biomarkers with high sensitivity and specificity. An oral cancer study found that the sensor had approximately $90 \%$ specificity and sensitivity for $I L-8$ mRNA and IL-8 protein with a limit of detection of $3.9 \mathrm{f}$. and $7.4 \mathrm{pg} / \mathrm{mL}$, respectively [92]. The final product, called the Oral Fluid NanoSensor Test (OFNASET), is an automated and easy-to-use system able to quickly and simultaneously detect multiple salivary protein and nucleic acid targets for the determination of various diseases. This point-of-care electrochemical sensor system can be used in the office of a dentist or another healthcare provider to deliver quick disease screening results [93-95].

Furthermore, to allow for an accurate assessment of biomarkers, researchers should follow the Prospective Specimen Collection, Retrospective Blinded Evaluation (PRoBE) design in which biological specimens are collected from a cohort population that resembles the population where the biomarker will be used. For example, a study to determine the sensitivity and specificity of a particular marker for OSCC would need to be tested in a population at high risk for developing the cancer. The second part of the PRoBE design ensures that subject diagnoses are blinded to obtain unbiased data on biomarker specificity and sensitivity [96]. Currently, a nationwide PRoBE design study for OSCC saliva biomarkers is underway that meets the guidelines of the NIH. Dr. David Wong and his team at the University of California, Los Angeles, are enrolling subjects to validate salivary oral cancer biomarkers and determine the performance of already discovered transcriptomic and proteomic panels. OSCC is multi-factorial with a heterogenic pathogenesis; thus, one single biomarker may not be able to discriminate between OSCC and controls. Multiple biomarker candidates are needed for high accuracy and sensitivity in detecting OSCC. A combination of the transcriptomic and proteomic salivary biomarkers was tested in an independent cohort of OSCC patients from Serbia. Three protein markers (IL-8, IL-1 $\beta$, and M2BP) and four mRNA markers (IL-8, IL$1 \beta, S A T 1$, and $S 100 P$ ) were elevated and discriminatory for late-stage OSCC [64••, 65••, 97].

Early detection of premalignant lesions is associated with improved survival in OSCC patients. Unfortunately, most OSCC cases are detected when the cancer has developed into the advanced stages. Biopsies have several disadvantages, including relatively high costs, inaccurate diagnoses because of difficulties in sampling tissue, and patient discomfort with the procedure. Reliable early-stage diagnostic markers for OSCC are currently lacking. Sensitive and specific biomarkers for OSCC will be helpful in screening high-risk patients and to follow up patients for early signs of recurrence. Furthermore, salivary biomarkers can be used between biopsies to assist in monitoring the disease status of dysplasia patients. Although extensive and thorough biomarker validation is essential before any biomarker candidates can be tailored for clinical use, salivary diagnostics for OSCC are very promising because of the direct contact of saliva with premalignant or malignant lesions.

Acknowledgments Supported by research grants UH2 TR000923, U01DE17593, R01 CA139596, R56 DE23241, R01 DE17170, and R21 CA0126733 and the Barnes Family Fund for Head and Neck Cancer Research.

\section{Compliance with Ethics Guidelines}

Conflict of Interest Dr. Maha Yakob received a grant from the NIH. Dr. Laurel Fuentes received a grant from the NIH.

Dr. Marilene B. Wang and Dr. Elliot Abemayor each declare no potential conflicts of interest relevant to this article.

Dr. David T.W. Wong is a co-founder of RNAmeTRIX Inc., a molecular diagnostic company. He holds equity in RNAmeTRIX, and serves as a company Director and Scientific Advisor. The University of California, 
Los Angeles also holds equity in RNAmeTRIX. Intellectual property that David Wong invented and that was patented by the University of California. Los Angeles has been licensed to RNAmeTRIX. Additionally, he is a paid consultant to PeriRx.

Human and Animal Rights and Informed Consent This article does not contain any studies with human or animal subjects performed by any of the authors.

\section{References}

Papers of particular interest, published recently, have been highlighted as:

- Of importance

•- Of major importance

1. Siegel R, Naishadham D, Jemal A. Cancer statistics, 2013. CA Cancer J Clin. 2013;63(1):11-30.

2. Markopoulos AK. Current aspects on oral squamous cell carcinoma. Open Dent J. 2012;6:126-30.

3. Ferlay J, Shin HR, Bray F, Forman D, Mathers C, Parkin DM. Estimates of worldwide burden of cancer in 2008: GLOBOCAN 2008. Int J Cancer. 2010;27(12):2893-917.

4. Parkin DM, Bray F, Ferlay J, Pisani P. Global cancer statistics, 2002. CA Cancer J Clin. 2005;55(2):74-108.

5. Oral health in America: a report of the Surgeon General. J Calif Dent Assoc. 2000;28(9):685-695.

6. Choi S, Myers JN. Molecular pathogenesis of oral squamous cell carcinoma: implications for therapy. J Dent Res. 2008;87(1):14-32.

7. Zini A, Czerninski R, Sgan-Cohen HD. Oral cancer over four decades: epidemiology, trends, histology, and survival by anatomical sites. J Oral Pathol Med. 2010;39(4):299-305.

8. Decker J, Goldstein JC. Risk factors in head and neck cancer. N Engl J Med. 1982;306(19):1151-5.

9. Sugimura T, Kumimoto H, Tohnai I, Fukui T, Matsuo K, Tsurusako $\mathrm{S}$, et al. Gene-environment interaction involved in oral carcinogenesis: molecular epidemiological study for metabolic and DNA repair gene polymorphisms. J Oral Pathol Med. 2006;35(1):11-8.

10. Brennan JA, Boyle JO, Koch WM, Goodman SN, Hruban RH, Eby YJ, et al. Association between cigarette smoking and mutation of the p53 gene in squamous-cell carcinoma of the head and neck. N Engl J Med. 1995;332(11):712-7.

11. Napier SS, Speight PM. Natural history of potentially malignant oral lesions and conditions: an overview of the literature. J Oral Pathol Med. 2008;37(1):1-10.

12. Reibel J. Prognosis of oral pre-malignant lesions: significance of clinical, histopathological, and molecular biological characteristics. Crit Rev Oral Biol Med. 2003;14(1):47-62.

13. Mücke T, Wagenpfeil S, Kesting MR, Hölzle F, Wolff KD. Recurrence interval affects survival after local relapse of oral cancer. Oral Oncol. 2009;45(8):687-91.

14. Sklenicka S, Gardiner S, Dierks EJ, Potter BE, Bell RB. Survival analysis and risk factors for recurrence in oral squamous cell carcinoma: does surgical salvage affect outcome? J Oral Maxillofac Surg. 2010;68(6):1270-5.

15. Gonzalez-Garcia R, Naval-Gias L, Roman-Romero L, Sastre-Perez J, Rodriguez-Campo FJ. Local recurrences and second primary tumors from squamous cell carcinoma of the oral cavity: a retrospective analytic study of 500 patients. Head Neck. 2009;31(9): 1168-80.

16. Tabor MP, Brakenhoff RH, Ruijter-Schippers HJ, Kummer JA, Leemans CR, Braakhuis BJ. Genetically altered fields as origin of locally recurrent head and neck cancer: a retrospective study. Clin Cancer Res. 2004;10(11):3607-13.

17. Tabor MP, Brakenhoff RH, Ruijter-Schippers HJ, Van Der Wal JE, Snow GB, Leemans CR, et al. Multiple head and neck tumors frequently originate from a single preneoplastic lesion. Am J Pathol. 2002;161(3):1051-60.

18. Tabor MP, Brakenhoff RH, van Houten VM, Kummer JA, Snel MH, Snijders PJ, et al. Persistence of genetically altered fields in head and neck cancer patients: biological and clinical implications. Clin Cancer Res. 2001;7(6):1523-32.

19. Warnakulasuriya S. Global epidemiology of oral and oropharyngeal cancer. Oral Oncol. 2009;45(4-5):309-16.

20. Peacock ZS, Pogrel MA, Schmidt BL. Exploring the reasons for delay in treatment of oral cancer. J Am Dent Assoc. 2008;139(10): 1346-52.

21. Chiappin S, Antonelli G, Gatti R, De Palo EF. Saliva specimen: a new laboratory tool for diagnostic and basic investigation. Clin Chim Acta. 2007;383(1-2):30-40.

22. Humphrey SP, Williamson RT. A review of saliva: normal composition, flow, and function. J Prosthetic Dent. 2001;85(2):162-69.

23. Amerongen AV, Bolscher JGM, Veerman ECI. Salivary proteins: protective and diagnostic value in cariology? Caries Res. 2004;38(3): 247-53.

24. Liu J, Duan Y. Saliva: a potential media for disease diagnostics and monitoring. Oral Oncol. 2012;48(7):569-77.

25. de Almeida PV, Grégio AM, Machado MA, de Lima AA, Azevedo LR. Saliva composition and functions: a comprehensive review. J Contemp Dent Pract. 2008;9(3):72-80.

26. Dodds MWJ, Johnson DA, Yeh CK. Health benefits of saliva: a review. J Dent. 2005;33(3):223-33.

27. Mohamed R, Campbell JL, Cooper-White J, Dimeski G, Punyadeera $\mathrm{C}$. The impact of saliva collection and processing methods on CRP, IgE, and myoglobin immunoassays. Clin Transl Med. 2012;1(1): 19 .

28. Principe S, Hui ABY, Bruce J, Sinha A, Liu FF, Kislinger T. Tumorderived exosomes and microvesicles in head and neck cancer: implications for tumor biology and biomarker discovery. Proteomics. 2013;13(10-11):1608-23.

29. Bigler LR, Streckfus CF, Copeland L, Burns R, Dai XL, Kuhn M, et al. The potential use of saliva to detect recurrence of disease in women with breast carcinoma. J Oral Pathol Med. 2002;31(7):421-31.

30. Zhang L, Xiao H, Zhou H, Santiago S, Lee JM, Garon EB, et al. Development of transcriptomic biomarker signature in human saliva to detect lung cancer. Cell Mol Life Sci. 2012;69(19):3341-50.

31. Xiao H, Zhang L, Zhou H, Lee JM, Garon EB, Wong DTW. Proteomic analysis of human saliva from lung cancer patients using two-dimensional difference gel electrophoresis and mass spectrometry. Mol Cell Proteomics. 2012;11(2):M111.012112.

32. Gao K, Zhou H, Zhang L, Lee JW, Zhou Q, Hu S, et al. Systemic disease-induced salivary biomarker profiles in mouse models of melanoma and non-small cell lung cancer. PLoS One. 2009;4(6):e5875.

33. Hu S, Gao K, Pollard R, Arellano-Garcia M, Zhou H, Zhang L, et al. Preclinical validation of salivary biomarkers for primary Sjögren's syndrome. Arthritis Care Res. 2010;62(11):1633-8.

34. Sugimoto M, Wong DT, Hirayama A, Soga T, Tomita M. Capillary electrophoresis mass spectrometry-based saliva metabolomics identified oral, breast and pancreatic cancer-specific profiles. Metabolomics. 2010;6(1):78-95.

35. Lau C, Kim Y, Chia D, Spielmann N, Eibl G, Elashoff D, et al. Role of pancreatic cancer-derived exosomes in salivary biomarker development. J Biol Chem. 2013;288(37):26888-97.

36. Ilyin SE, Belkowski SM, Plata-Salaman CR. Biomarker discovery and validation: technologies and integrative approaches. Trends Biotechnol. 2004;22(8):411-6.

37. Silberring J, Ciborowski P. Biomarker discovery and clinical proteomics. Trends Anal Chem. 2010;29(2):128-40. 
38. Chen W, Samuelson FW, Gallas BD, Kang L, Sahiner B, Petrick N. On the assessment of the added value of new predictive biomarkers. BMC Med Res Methodol. 2013;13:98.

39. Warnock DG, Peck CC. A roadmap for biomarker qualification. Nat Biotechnol. 2010;28(5):444-5.

40. Bryne M, Koppang HS, Lilleng R, Kjaerheim A. Malignancy grading of the deep invasive margins of oral squamous cell carcinomas has high prognostic value. J Pathol. 1992;166(4):375-81.

41. Akhter M, Hossain S, Rahman QB, Molla MR. A study on histological grading of oral squamous cell carcinoma and its corelationship with regional metastasis. J Oral Maxillofac Pathol. 2011;15(2):168-76.

42. Rusthoven K, Ballonoff A, Raben D, Chen C. Poor prognosis in patients with stage I and II oral tongue squamous cell carcinoma. Cancer. 2008;112(2):345-51.

43. Anneroth G, Batsakis J, Luna M. Review of the literature and a recommended system of malignancy grading in oral squamous cell carcinomas. Scand J Dent Res. 1987;95(3):229-49.

43. Wong DT. Salivaomics. J Am Dent Assoc. 2012;143(10 Suppl): 19S-24S. This paper coined the term salivaomics to reflect the important advancements in salivary diagnostics through the development of omics-based biomarkers.

45. Dowling P, Wormald R, Meleady P, Henry M, Curran A, Clynes M. Analysis of the saliva proteome from patients with head and neck squamous cell carcinoma reveals differences in abundance levels of proteins associated with tumour progression and metastasis. $\mathrm{J}$ Proteomics. 2008;71(2):168-75.

46. Arellano-Garcia ME, Hu S, Wang J, Henson B, Zhou H, Chia D, et al. Multiplexed immunobead-based assay for detection of oral cancer protein biomarkers in saliva. Oral Dis. 2008;14(8):705-12.

47. Denny P, Hagen FK, Hardt M, Liao LJ, Yan WH, Arellanno M, et al. The proteomes of human parotid and submandibular/ sublingual gland salivas collected as the ductal secretions. J Proteome Res. 2008;7(5):1994-2006.

48. Loo JA, Yan W, Ramachandran P, Wong DT. Comparative human salivary and plasma proteomes. J Dent Res. 2010;89(10):1016-23.

49. Bonne NJ, Wong DTW. Salivary biomarker development using genomic, proteomic and metabolomic approaches. Genome Med. 2012;4:82

50. Sorsa T, Tjaderhane L, Salo T. Matrix metalloproteinases (MMPs) in oral diseases. Oral Dis. 2004;10(6):311-8.

51. Stott-Miller M, Houck JR, Lohavanichbutr P, Mendez E, Upton MP, Futran ND, et al. Tumor and salivary matrix metalloproteinase levels are strong diagnostic markers of oral squamous cell carcinoma. Cancer Epidemiol Biomarkers Prev. 2011;20(12):2628-36.

52. Shpitzer T, Hamzany Y, Bahar G, Feinmesser R, Savulescu D, Borovoi I, et al. Salivary analysis of oral cancer biomarkers. Br J Cancer. 2009;101(7):1194-8.

53. Rusthoven KE, Raben D, Song JI, Kane M, Altoos TA, Chen CH. Survival and patterns of relapse in patients with oral tongue cancer. J Oral Maxillofac Surg. 2010;68(3):584-9.

54. Korostoff A, Reder L, Masood R, Sinha UK. The role of salivary cytokine biomarkers in tongue cancer invasion and mortality. Oral Oncol. 2011;47(4):282-7.

55. Hu S, Arellano M, Boontheung P, Wang J, Zhou H, Jiang J, et al. Salivary proteomics for oral cancer biomarker discovery. Clin Cancer Res. 2008;14(19):6246-52.

56. de Jong EP, Xie HW, Onsongo G, Stone MD, Chen XB, Kooren JA, et al. Quantitative proteomics reveals myosin and actin as promising saliva biomarkers for distinguishing pre-malignant and malignant oral lesions. PLoS One. 2010;5(6):e11148.

57. Jou Y-J, Lin C-D, Lai C-H, Chen C-H, Kao J-Y, Chen S-Y, et al. Proteomic identification of salivary transferrin as a biomarker for early detection of oral cancer. Anal Chim Acta. 2010;681(1-2):41-8.
58. Wu ZL, Zhang L, Yabe T, Kuberan B, Beeler DL, Love A, et al. The involvement of heparan sulfate (HS) in FGF1/HS/FGFR1 signaling complex. J Biol Chem. 2003;278(19):17121-9.

59. Burgess WH, Maciag T. The heparin-binding (fibroblast) growth factor family of proteins. Annu Rev Biochem. 1989;58:575-606.

60. Baird A, Walicke PA. Fibroblast growth factors. Br Med Bull. 1989;45(2):438-52.

61. Gorugantula LM, Rees T, Plemons J, Chen H-S, Cheng Y-SL. Salivary basic fibroblast growth factor in patients with oral squamous cell carcinoma or oral lichen planus. Oral Surg Oral Med Oral Pathol Oral Radiol. 2012;114(2):215-22.

62. Vajaria BN, Patel KR, Begum R, Shah FD, Patel JB, Shukla SN, et al. Evaluation of serum and salivary total sialic acid and alpha-Lfucosidase in patients with oral precancerous conditions and oral cancer. Oral Surg Oral Med Oral Pathol Oral Radiol. 2013;115(6): 764-71.

63. Li Y, St John MAR, Zhou XF, Kim Y, Sinha U, Jordan RCK, et al. Salivary transcriptome diagnostics for oral cancer detection. Clin Cancer Res. 2004;10(24):8442-50.

63.• Elashoff D, Zhou H, Reiss J, Wang J, Xiao H, Henson B, et al Prevalidation of salivary biomarkers for oral cancer detection. Cancer Epidemiol Biomarkers Prev. 2012;21(4):664-72. The study validated a panel of seven $m R N A$ s and three proteins that previously were reported to be capable of discriminating patients with oral squamous cell carcinoma from healthy subjects in independent cohorts.

64.• Brinkmann O, Kastratovic DA, Dimitrijevic MV, Konstantinovic VS, Jelovac DB, Antic J, et al. Oral squamous cell carcinoma detection by salivary biomarkers in a Serbian population. Oral Oncol. 2011;47(1):51-5. The study showed that the previously discovered and validated biomarkers were discriminatory and reproducible in a different ethnic cohort.

66. Ziober AF, Patel KR, Alawi F, Gimotty P, Weber RS, Feldman MM, et al. Identification of a gene signature for rapid screening of oral squamous cell carcinoma. Clin Cancer Res. 2006;12(20):5960-71.

67. Yen CY, Chen $\mathrm{CH}$, Chang CH, Tseng HF, Liu SY, Chuang LY, et al. Matrix metalloproteinases (MMP) 1 and MMP10 but not MMP12 are potential oral cancer markers. Biomarkers. 2009;14(4):244-9.

68. Jordan RCK, Macabeo-Ong M, Shiboski CH, Dekker N, Ginzinger DG, Wong DTW, et al. Overexpression of matrix metalloproteinase-1 and-9 mRNA is associated with progression of oral dysplasia to cancer. Clin Cancer Res. 2004;10(19):6460-5.

69. Lallemant B, Evrard A, Combescure C, Chapuis H, Chambon G, Raynal C, et al. Clinical relevance of nine transcriptional molecular markers for the diagnosis of head and neck squamous cell carcinoma in tissue and saliva rinse. BMC Cancer. 2009;9:370.

70. Zeng Y. Principles of micro-RNA production and maturation. Oncogene. 2006;25(46):6156-62.

71. Chang TC, Mendell JT. microRNAs in vertebrate physiology and human disease. Annu Rev Genomics Hum Genet. 2007;8:215-39.

72. Liu C-J, Lin S-C, Yang C-C, Cheng H-W, Chang K-W. Exploiting salivary miR-31 as a clinical biomarker of oral squamous cell carcinoma. Head Neck. 2012;34(2):219-24.

73. Chang KW, Liu CJ, Chu TH, Cheng HW, Hung PS, Hu WY, et al. Association between high miR-211 microRNA expression and the poor prognosis of oral carcinoma. J Dent Res. 2008;87(11):1063-8.

73.• Park NJ, Zhou H, Elashoff D, Henson BS, Kastratovic DA, Abemayor E, et al. Salivary microRNA: discovery, characterization, and clinical utility for oral cancer detection. Clin Cancer Res. 2009;15(17):5473-7. The presence of microRNA in saliva was demonstrated and approximately 50 miRNAs were detected in healthy saliva. Furthermore, significantly lower levels of miR$125 a$ and mi-R200a were in the saliva from oral squamous cell carcinoma patients compared with healthy control subjects.

75. Spielmann N, Wong DT. Saliva: diagnostics and therapeutic perspectives. Oral Dis. 2011;17(4):345-54. 
76. Dewhirst FE, Chen T, Izard J, Paster BJ, Tanner ACR, Yu WH, et al. The human oral microbiome. J Bacteriol. 2012;192(19):5002-17.

77. Glurich I, Acharya A, Shukla SK, Nycz GR, Brilliant MH. The oral-systemic personalized medicine model at Marshfield Clinic. Oral Dis. 2013;19(1):1-17.

78. Pushalkar S, Ji X, Li Y, Estilo C, Yegnanarayana R, Singh B, et al. Comparison of oral microbiota in tumor and non-tumor tissues of patients with oral squamous cell carcinoma. BMC Microbiol. 2012;12:144.

78. Pushalkar S, Mane SP, Ji X, Li Y, Evans C, Crasta OR, et al. Microbial diversity in saliva of oral squamous cell carcinoma. FEMS Immunol Med Microbiol. 2011;61(3):269-77. Microbial diversity was shown in saliva of oral squamous cell carcinoma (OSCC), as well as the presence of common phylotypes associated with OSCC or controls. The findings are of importance because they reflect the repopulation or shift in microbial communities.

80. Marur S, D'Souza G, Westra WH, Forastiere A. HPV-associated head and neck cancer: a virus-related cancer epidemic. Lancet Oncol. 2010;11(8):781-9.

81. Viet CT, Schmidt BL. Methylation array analysis of preoperative and postoperative saliva DNA in crab cancer patients. Cancer Epidemiol Biomarkers Prev. 2008;17(12):3603-11.

81.• Jithesh PV, Risk JM, Schache AG, Dhanda J, Lane B, Liloglou T, et al. The epigenetic landscape of oral squamous cell carcinoma. $\mathrm{Br}$ J Cancer. 2013;108(2):370-9. This paper illustrates the application of epigenetic biomarkers and targets available to further the development of therapy in oral squamous cell carcinoma.

83. Guerrero-Preston R, Soudry E, Acero J, Orera M, Moreno-Lopez L, Macia-Colon G, et al. NID2 and HOXA9 promoter hypermethylation as biomarkers for prevention and early detection in oral cavity squamous cell carcinoma tissues and saliva. Cancer Prev Res. 2011;4(7):1061-72.

84. Xia J, Broadhurst DI, Wilson M, Wishart DS. Translational biomarker discovery in clinical metabolomics: an introductory tutorial. Metabolomics. 2013;9(2):280-99.

85. Patti GJ, Yanes O, Siuzdak G. Innovation: metabolomics: the apogee of the omics trilogy. Nat Rev Mol Cell Biol. 2012;13(4): 263-9.
86. Tripathi P, Kamarajan P, Somashekar BS, MacKinnon N, Chinnaiyan AM, Kapila YL, et al. Delineating metabolic signatures of head and neck squamous cell carcinoma: phospholipase A2, a potential therapeutic target. Int J Biochem Cell Biol. 2012;44(11): 1852-61.

87. Lee Y, El Andaloussi S, Wood MJ. Exosomes and microvesicles: extracellular vesicles for genetic information transfer and gene therapy. Hum Mol Genet. 2012;21(R1):R125-134.

88. Ogawa Y, Miura Y, Harazono A, Kanai-Azuma M, Akimoto Y, Kawakami H, et al. Proteomic analysis of two types of exosomes in human whole saliva. Biol Pharm Bull. 2011;34(1):13-23.

89. Ogawa Y, Kanai-Azuma M, Akimoto Y, Kawakami H, Yanoshita R. Exosome-like vesicles with dipeptidyl peptidase IV in human saliva. Biol Pharm Bull. 2008;31(6):1059-62.

90. Kim JW, Wieckowski E, Taylor DD, Reichert TE, Watkins S, Whiteside TL. Fas ligand-positive membranous vesicles isolated from sera of patients with oral cancer induce apoptosis of activated T lymphocytes. Clin Cancer Res. 2005;11(3):1010-20.

91. Wong DT. Salivary diagnostics powered by nanotechnologies, proteomics and genomics. J Am Dent Assoc. 2006;137(3):313-21.

92. Wei F, Patel P, Liao W, Chaudhry K, Zhang L, Arellano-Garcia M, et al. Electrochemical sensor for multiplex biomarkers detection. Clin Cancer Res. 2009;15(13):4446-52.

93. Gau V, Wong D. Oral fluid nanosensor test (OFNASET) with advanced electrochemical-based molecular analysis platform. Ann N Y Acad Sci. 2007;1098:401-10.

94. Pujari M, Bahirwani S, Balaji P, Kaul R, Shah B, Daryani D, et al. Oral fluid nanosensor test: saliva as a diagnostic tool for oral health. J Calif Dent Assoc. 2012;40(9):733-6.

95. Wei F, Wong DT. Point-of-care platforms for salivary diagnostics. Chin J Dent Res. 2012;15(1):7-15.

96. Pepe MS, Feng Z, Janes H, Bossuyt PM, Potter JD. Pivotal evaluation of the accuracy of a biomarker used for classification or prediction: standards for study design. J Natl Cancer Inst. 2008;100(20):1432-8.

97. Brinkman BMN, Wong DTW. Disease mechanism and biomarkers of oral squamous cell carcinoma. Curr Opin Oncol. 2006;18(3): 228-33. 